\title{
Finite Element Based Response Surface Methodology to Optimize Segmental Tunnel Lining
}

\author{
Armin Rastbood \\ School of Mining Engineering \\ College of Engineering, University \\ of Tehran \\ Tehran, Iran \\ arminrastbood88@gmail.com
}

\author{
Yaghoob Gholipour \\ School of Civil Engineering \\ College of Engineering, University \\ of Tehran \\ Tehran, Iran \\ ygholipour@ut.ac.ir
}

\author{
Abbas Majdi \\ School of Mining Engineering \\ College of Engineering, University \\ of Tehran \\ Tehran, Iran \\ amajdi@ut.ac.ir
}

\begin{abstract}
The main objective of this paper is to optimize the geometrical and engineering characteristics of concrete segments of tunnel lining using Finite Element (FE) based Response Surface Methodology (RSM). Input data for RSM statistical analysis were obtained using FEM. In RSM analysis, thickness (t) and elasticity modulus of concrete segments (E), tunnel height $(H)$, horizontal to vertical stress ratio $(K)$ and position of key segment in tunnel lining ring $(\theta)$ were considered as input independent variables. Maximum values of Mises and Tresca stresses and tunnel ring displacement (UMAX) were set as responses. Analysis of variance (ANOVA) was carried out to investigate the influence of each input variable on the responses. Second-order polynomial equations in terms of influencing input variables were obtained for each response. It was found that elasticity modulus and key segment position variables were not included in yield stresses and ring displacement equations, and only tunnel height and stress ratio variables were included in ring displacement equation. Finally optimization analysis of tunnel lining ring was performed. Due to absence of elasticity modulus and key segment position variables in equations, their values were kept to average level and other variables were floated in related ranges. Response parameters were set to minimum. It was concluded that to obtain optimum values for responses, ring thickness and tunnel height must be near to their maximum and minimum values, respectively and ground state must be similar to hydrostatic conditions.
\end{abstract}

Keywords-tunnel; segment; lining; response surface methodology; analysis of variance

\section{INTRODUCTION}

Nowadays, most number of the tunnels are excavated using shield tunneling method in soft ground conditions, because this type of tunneling is rapid, cost effectiveness and has minimum effect on surrounding environment. In general, this type of tunneling uses concrete segments as a tunnel support system. Assembling concrete segments to each other in one excavation step forms a structure named ring [1,2]. Usually, the number of erected segments in a ring is more than four. Successive rings compose a final support system of the tunnel, called lining. One of the segments in a ring is designed usually smaller than the other segments and is called the key segment. This causes the facility both in ring erection and excavation operation in curved alignments. Key segment will be installed at the end of ring assembling operation. In Figures 1 and 2 some nomenclatures of tunnel lining support system are illustrated.

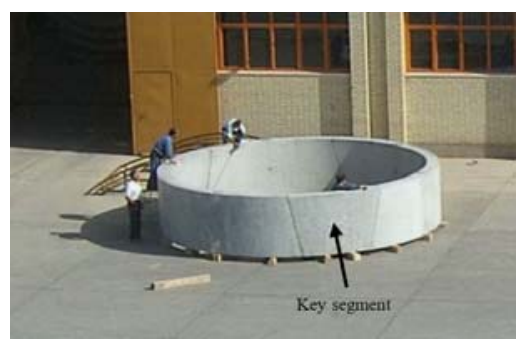

Fig. 1. Assembled ring in segment manufacturing factory, Tabriz metroLine 1

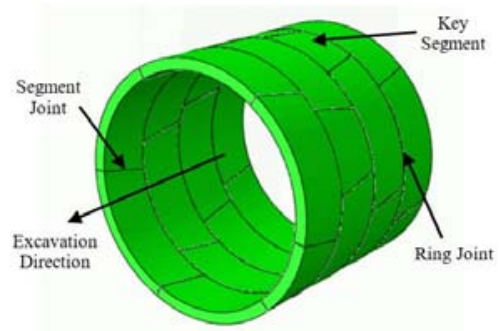

Fig. 2. Tunnel lining structure

Concrete segments have a complicated process from the design and construction points of view [3]. The final design of concrete segments must provide optimized ring bearing capacity against different types of loads both in Ultimate Limit State (ULS) and Serviceability Limit State (SLS) [4, 5]. In [6], an experimental equation to calculate the reduced effective moment of inertia of a ring with joints was proposed. The proposed equation includes segment number and joint stiffness parameter:

$$
\mathrm{I}_{\mathrm{e}}=\mathrm{I}_{\mathrm{j}}+\left(\frac{4}{\mathrm{n}}\right)^{2} . \mathrm{I} \quad \mathrm{I}_{\mathrm{e}} \leq \mathrm{I}, \mathrm{n}>4
$$

Where $I_{e}$ is effective moment of inertia of jointed ring, $I_{j}$ is moment of inertia in the joints, $I$ is the moment of inertia of a continuous ring without joints and $\mathrm{n}$ is the number of segments. 
In [7], authors discussed about the main differences in the assumptions for three different models: the continuum ring model, the Muir Wood design model and the bedded beam model without bedding at the tunnel lining crown region. In [8], authors presented a comparative study between spatial (3D) computing static models and theoretical results of commonly used plain (2D) computing models for segmental tunnel lining. Comprehensive methods for determination of structural forces in tunnel lining and segment design were presented in [9]. In [10], authors categorized all tunnel lining design methods into four major types: (a) empirical design methods; (b) experimental and laboratory modelling; (c) circular ring in elastic foundation model; and (d) continuum mechanics models including analytical methods and numerical methods. Four most important models of tunnel lining structure by considering ring and segment joints are illustrated in [11]. In [12], authors discussed about the various load types imposed on shield machine and tunnel lining. In [13], authors performed a full scale test on three-rings of segmental lining structure of the Shanghai Changjiang tunnel with a diameter of $15 \mathrm{~m}$. In [14], author conducted a series of tests on small laboratory segmental tunnel lining were made from PVC to obtain their load bearing capacity. In this study authors focused on simple beam support tests to estimate joint stiffness. A comprehensive numerical model using 2D finite difference element model was proposed in [15]. In this paper many factors that influence tunnel lining behavior together with three different types of joint springs, i.e. rotational, axial and radial springs were modeled.

Some analytical solution are available for segmental tunnel lining design, as those proposed in [7, 16-19]. In [10], authors introduced an analytical equation for moment reduction factor based on the maximum horizontal displacement of a uniform ring. An analytical solution for analyzing tunnel lining in longitudinal direction was proposed in [20]. In [21], authors studied the elastic analysis of a circular lined tunnel by considering the delayed installation of the tunnel support. Recently, many publications about numerical modelling of segmental tunnel lining both in $2 \mathrm{D}$ and $3 \mathrm{D}$, considering more detailed aspects of shield tunneling were published [15, 22-25].

Despite most comprehensive available attempts based on different approaches to analyze segmental tunnel lining in various point of view, there are no considerable publications in this field using statistical methods. In this paper, FEM based Response Surface Methodology (RSM) approach was organized to establish statistical equations between tunnel lining characteristics as input variables and generated stresses and displacements in tunnel lining structure as responses parameters using analysis of variance (ANOVA). Finally optimization analysis was performed for each response parameter in terms of input variables.

\section{NUMERICAL MODELLING}

In this study, input data for statistical analysis, called experiments from now on, were obtained using the finite element method (ABAQUS [26]). In all FEM models, one ring of tunnel lining support system composed from 5+1 segments. Table I shows the engineering and geometrical characteristics of the concrete segments. The behavior of the tunnel lining is assumed to be elastic. In a ring, the shape of the five segments (A2-A6) are similar to each other except for the key segment (A1) which is smaller. In all numerical models, it is assumed that the ring is positioned far away from the tunnel face and is not influenced by shield machine loads and tunneling operation. Beam-spring model introduced in [27] was used in numerical modeling. This type of segmental tunnel lining is proposed in several tunneling guidelines $[9,19]$. Interaction of ground on outer surface of tunnel lining was simulated using tangential and normal springs. Stiffness of ground normal springs is evaluated using (2), [28, 29]:

$$
\mathrm{K}_{\mathrm{n}}=\mathrm{A} \cdot \mathrm{E} / \mathrm{R} .(1+\mathrm{v})(2)
$$

Where $K_{n}$ is the stiffness of radial spring, $E$ and $v$ are the elasticity modulus and poison's ratio of soil respectively, R is the tunnel radius, and A represents the effective area of tunnel lining that is subjected to implied force from the soil, and is calculated using (3):

$$
\mathrm{A}=\mathrm{R} \theta \cdot \mathrm{b}(3)
$$

Where $\theta$ is radial angle between two successive radial springs applied on lining surface, and $\mathrm{b}$ represents effective area of each spring in tunnel longitudinal direction.

The stiffness of tangential springs $\left(\mathrm{K}_{\mathrm{t}}\right)$ is assumed to be one-third of the normal spring stiffness (Figure 3) [34]. The ring under the impact of interaction springs and surrounding ground load is shown in Figures $4 \mathrm{a}$ and $4 \mathrm{~b}$ respectively. 3D solid-stress elements with linear geometric order were used to model concrete segments (Figure 5a). Plane strain condition was considered in the models. Also according to the literature, in transverse direction the segmental lining structure is usually designed in plane strain condition [9, 30-33]. In this study, it is assumed that origin of angle in transverse section of the model is positioned at tunnel crown (Figure 5b). Longitudinal joints of assembled segments in a ring and key segment position at $\theta=90^{\circ}$ are shown in Figure 5c. Hard contact was assumed for interaction of six concrete to concrete contact surfaces in segment joints with frictional penalty coefficient of 0.4 .

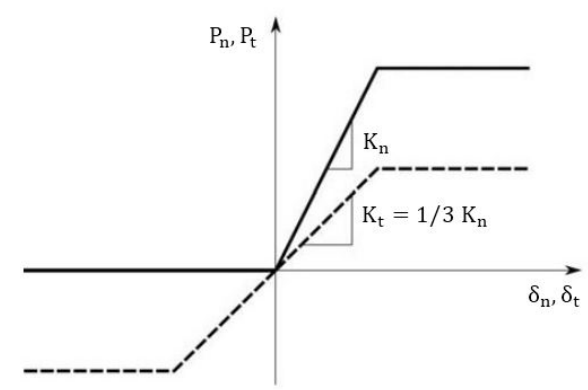

Fig. 3. Constitutive relationship of the springs representing the ground reaction in the bedded-spring model. Pn and Pt represent the normal and tangential load, $\delta_{n}$ and $\delta_{t}$ are the normal and tangential displacement; $\mathrm{K}_{\mathrm{n}}$ and $\mathrm{K}_{\mathrm{t}}$ are the normal and tangential stiffness

\section{A. Input data preparation for statistical RSM analysis}

The numerical model first was solved for $\mathrm{t}$ (concrete segment thickness) $=30 \mathrm{~cm}$, tunnel overburden $\mathrm{H}=5 \mathrm{~m}, \mathrm{~K}=0.5$ (horizontal to vertical stress ratio), $\mathrm{E}$ (lining) $=20 \mathrm{GPa}$ and $\theta=0^{\circ}$ 
(key position at crown). Then $\mathrm{t}, \mathrm{H}, \mathrm{K}$ and $\mathrm{E}$ values were kept constant and $\theta$ value changed $30^{\circ}, 60^{\circ}, 90^{\circ}, 120^{\circ}, 150^{\circ}$ and $180^{\circ}$ respectively. To prepare enough input data for statistical RSM, for each value of input variables, values of other input variables were changed according to the rule presented in Table II. These variables considered as input independent variables in statistical analysis. This table shows times of changes for each input variable and its value. Due to the axisymmetric shape of the ring, key positions at $210^{\circ}, 240^{\circ}, 270^{\circ}, 300^{\circ}$ and $330^{\circ}$ at lining periphery were neglected. Finally 252 numerical models were analyzed.

TABLE I. ENGINEERING AND GEOMETRICAL PROPERTIES OF CONCRETE SEGMENTS

\begin{tabular}{|c|c|c|c|c|c|}
\hline \multirow{2}{*}{$\begin{array}{c}\text { Segment } \\
\text { No. }\end{array}$} & \multicolumn{2}{|c|}{ Engineering properties } & \multicolumn{2}{|c|}{ Geometrical properties } \\
\cline { 2 - 6 } & $\boldsymbol{E}^{*}$ & $\boldsymbol{v}^{* *}$ & $\boldsymbol{\rho} * * *$ & $\boldsymbol{t} * * * *$ & Central angle $\left({ }^{*}\right)$ \\
\hline $\begin{array}{c}\text { A1(key } \\
\text { segment) }\end{array}$ & 20 & 0.15 & 2350 & 30 & 30 \\
\hline A2-A6 & & & & 66 \\
\hline
\end{tabular}
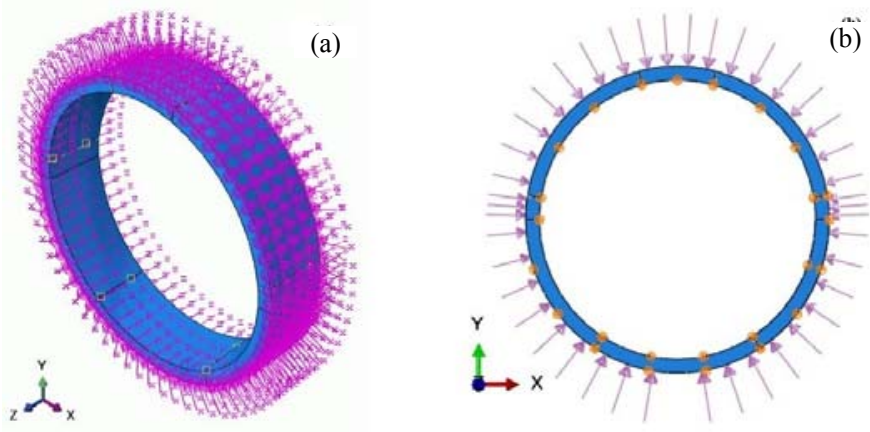

Fig. 4. Tunnel lining under ground springs and load: (a) ground radial and tangential springs, (b) surrounding ground load imposed on tunnel lining
Commonly, Tresca and Von Mises yield criteria are used as failure criteria for materials. According to Tresca yield criterion, material begins to yield when maximum absolute value of shear stress reaches to a critical value, and based on Von Mises yield criterion, material begins to yield when the second deviatoric stress invariant approaches to a critical value. So, due to importance of Tresca and Mises stresses, these both type of stresses together with ring displacement are considered for prediction analysis. Figures $6 \mathrm{a}, 6 \mathrm{~b}$ and $6 \mathrm{c}$ show extreme values resulted for Von Mises and Tresca stresses, and ring displacements for $\mathrm{t}=30 \mathrm{~cm}, \mathrm{H}=15 \mathrm{~m}, \mathrm{~K}=0.5, \mathrm{E}=20 \mathrm{GPa}$ and $\theta=0^{\circ}$. These output parameters considered as responses in statistical analysis.
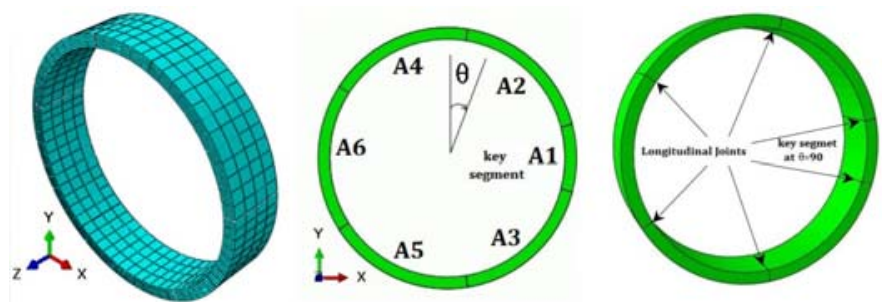

Fig. 5. Assembled ring of concrete segments: (a) Meshed Model, (b) Origin of $\theta$ angle, (c) Longitudinal joints and key position

TABLE II. DIFFERENT VALUES FOR INPUT VARIABLES

\begin{tabular}{|c|c|c|c|c|}
\hline \multicolumn{5}{|c|}{ Different values of 5 Input Variables } \\
\hline $\boldsymbol{t}(\mathbf{c m})$ & $\boldsymbol{H}(\boldsymbol{m})$ & $\boldsymbol{K}$ & $\boldsymbol{E}(\boldsymbol{G P a})$ & $\begin{array}{c}\text { Key } \\
\text { Position }\left({ }^{\circ}\right)\end{array}$ \\
\hline \multirow{3}{*}{30} & 5 & 0.5 & & 0 \\
& & & \multirow{2}{*}{20} & 30 \\
& \multirow{2}{*}{15} & \multirow{2}{*}{1.0} & & 60 \\
& & & \multirow{2}{*}{30} & 90 \\
& & & 35 & 120 \\
& 25 & 1.5 & & 180 \\
\hline
\end{tabular}
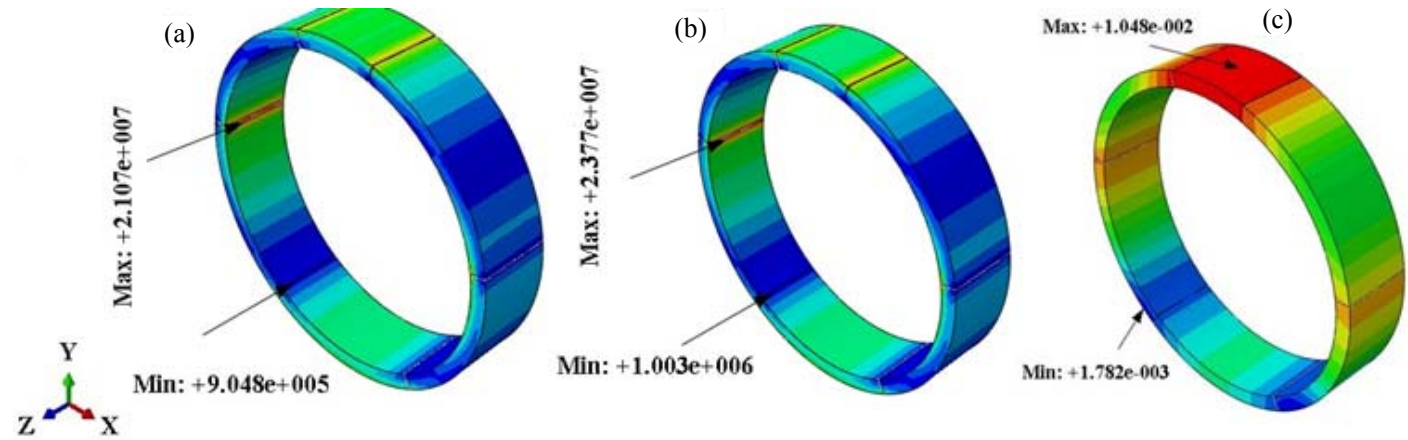

Fig. 6. Extreme values and distribution of (a) Von Mises stresses $\left(\mathrm{N} / \mathrm{m}^{2}\right),(\mathrm{b})$ Tresca stresses $\left(\mathrm{N} / \mathrm{m}^{2}\right)$ and $(\mathrm{c})$ ring displacements $(\mathrm{m})$ for $\mathrm{t}=30 \mathrm{~cm}$, $\mathrm{H}=15 \mathrm{~m}$, $\mathrm{K}=0.5, \mathrm{E}=20 \mathrm{GPa}$ and $\theta=0^{\circ}$.

\section{RESPONSE SURFACE METHODOLOGY}

Response surface methodology (RSM) is a collection of statistical and mathematical techniques useful for developing, improving, and optimizing processes [35]. In most RSM problems, the form of the relationship between the response and the independent variables is unknown. Thus, the first step in RSM is to find a suitable approximation for the true functional relationship between $\mathrm{y}$ and the set of independent variables [36]. Linear or square polynomial functions are employed to explain the considered problem. If there is 
curvature in the system, then a polynomial of higher degree must be used, such as the second-order model in (4):

$$
y=\beta_{0}+\sum_{i=1}^{k} \beta_{i} x_{i}+\sum_{i=1}^{k} \beta_{i i} x_{i}^{2}+\sum \sum \beta_{i j} x_{i} x_{j}+\varepsilon
$$

Where $\mathrm{y}$ is the response, $\mathrm{k}$ is the number of variables, $\beta_{0}$ is the constant term, $\beta_{\mathrm{i}}$ represents the coefficients of the linear parameters, $\beta_{\mathrm{ii}}$ represents the coefficients of the quadratic parameter, $\beta_{\mathrm{ij}}$ represents the coefficients of the interaction parameters, $\mathrm{x}_{\mathrm{i}}$ represents the variables, and $\varepsilon$ is the residual associated to the experiments [36].

RSM based statistical methodology is capable of optimizing the responses in terms of input variables. A flow chart of the RSM general procedure is shown in Figure 7. Quadratic regression equation was applied in RSM to establish equations between five input variables and three responses. In RSM, a series of analysis were conducted by Historical Data Design (HDD) using Design Expert 10.0.1 (State Ease, Inc., Minneapolis, MN, USA). Historical Data design enables the researcher to use data from a previous experiment or investigation. Any set of numeric or categoric data can be analyzed via Historical Data Design. As explained previously, 252 experiments conducted to provide data for statistical analysis. Some sample values of five factors and three responses are shown in Table III. Both for input variables and responses, their range, average value, ratio of maximum to minimum value, and standard deviation were as mentioned Tables IV and V, respectively.

TABLE III. PREPARED EXPERIMENTS FROM FINITE ELEMENT MODELING

\begin{tabular}{|c|c|c|c|c|c|c|c|c|}
\hline & Factor 1 & Factor 2 & Factor 3 & Factor 4 & Factor 5 & Response 1 & Response 2 & Response 3 \\
\hline Run & $\begin{array}{c}\text { A:Thickness } \\
(\mathbf{c m})\end{array}$ & $\boldsymbol{B}:$ Height $(\boldsymbol{m})$ & $\begin{array}{c}\text { C:K Ratio } \\
(--)\end{array}$ & $\begin{array}{c}\text { D:E Modulous } \\
(\mathbf{G p a})\end{array}$ & $\begin{array}{c}\text { E:Theta } \\
(\text { Degree })\end{array}$ & $\begin{array}{c}\text { MisesMax } \\
\left(\mathbf{N} / \boldsymbol{m}^{2}\right)\end{array}$ & $\begin{array}{c}\text { TrescaMax } \\
\left(\mathbf{N} / \boldsymbol{m}^{2}\right)\end{array}$ & $\begin{array}{c}\text { UMax } \\
(\boldsymbol{m})\end{array}$ \\
\hline 1 & 30.00 & 5.00 & 0.50 & 20.00 & 0.00 & $3.003 \mathrm{E}+006$ & $3.269 \mathrm{E}+006$ & 0.005132 \\
\hline 2 & 30.00 & 5.00 & 0.50 & 20.00 & 30.00 & $2.768 \mathrm{E}+006$ & $3.019 \mathrm{E}+006$ & 0.005211 \\
\hline 3 & 30.00 & 5.00 & 0.50 & 20.00 & 60.00 & $3.099 \mathrm{E}+006$ & $3.381 \mathrm{E}+006$ & 0.005242 \\
\hline$\ldots$ & $\ldots$ & $\ldots$ & $\ldots$ & $\ldots$ & $\ldots$ & $\ldots$ & $\ldots$ & $\ldots$ \\
\hline 252 & 40.00 & 25.00 & 1.50 & 35.00 & 180.00 & $3.222 \mathrm{E}+007$ & $3.465 \mathrm{E}+007$ & 0.02388 \\
\hline
\end{tabular}

TABLE IV. INPUT INDEPENDENT VARIABLES

\begin{tabular}{|c|c|c|c|c|c|}
\hline Name & Units & Minimum & Maximum & Mean & Standard deviation. \\
\hline Segment Thickness (A) & $\mathrm{cm}$ & 30.00 & 40.00 & 35.00 & 5.01 \\
\hline Height of tunnel (B) & $\mathrm{m}$ & 5.00 & 25.00 & 15.00 & 8.18 \\
\hline K (stress ratio) (C) & --- & 0.50 & 1.50 & 1.00 & 0.41 \\
\hline E (Elasticity Modulous) (D) & $\mathrm{GPa}$ & 20.00 & 35.00 & 27.50 & 7.51 \\
\hline$\theta$ (Key position) (E) & Degree & 0.00 & 180.00 & 90.00 & 60.12 \\
\hline
\end{tabular}

TABLE V. THREE RESPONSES OF RSM ANALYSIS

\begin{tabular}{|c|c|c|c|c|c|c|c|}
\hline Response Name & Units & Analysis & Minimum & Maximum & Mean & Standard Deviation. & Ratio \\
\hline Mises Max stress value & $\mathrm{N} / \mathrm{m}^{2}$ & Polynomial & $1.977 \mathrm{E}+006$ & $6.05 \mathrm{E}+007$ & $1.72815 \mathrm{E}+007$ & $1.37813 \mathrm{E}+007$ & 30.6019 \\
\hline Tresca Max stress value & $\mathrm{N} / \mathrm{m}^{2}$ & Polynomial & $2.115 \mathrm{E}+006$ & $6.896 \mathrm{E}+007$ & $1.91188 \mathrm{E}+007$ & $1.55427 \mathrm{E}+007$ & 32.6052 \\
\hline Displacement Max value & $\mathrm{m}$ & Polynomial & 0.004799 & 0.02973 & 0.0142558 & 0.00811969 & 6.19504 \\
\hline
\end{tabular}

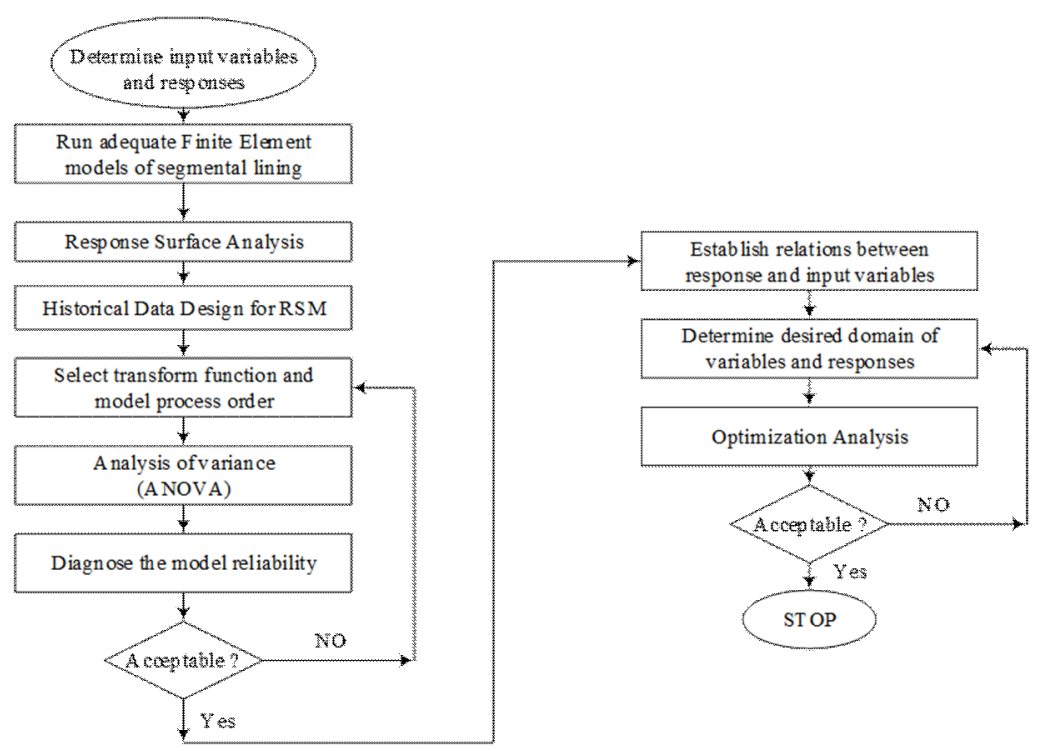

Fig. 7. FEM based RSM flow chart 


\section{A. Analysis of Variance (ANOVA)}

The fitted mathematical equation to the data using RSM may not adequately explain the considered experiment. Analysis of variance (ANOVA) is a method to assess the reliability of fitted function. The significance of regression can be evaluated by the ratio between the mean of the square of regression (MSreg) and the mean of the square of residuals (MSres), considering their related degrees of freedom. The higher value of this ratio (F-value) represents that the statistical model is fitted properly to the experimental data.

In this study, analysis of variance was used to evaluate the influence of each independent variable and their interactions on responses. Statistical parameters of three proposed models for maximum Misses stress, maximum Tresca stress and maximum ring displacement are illustrated in Table VI. The higher the Fvalue, the better the significance of the model. "Adequate Precision" measures the signal to noise ratio. A ratio greater than 4 is desirable. For three responses, actual data against predicted ones are shown in Figure 8. The evaluation of the fitted models is performed using the regression coefficient. Presented models approximately show satisfactory regression values. Also the predicted R-squared is in reasonable agreement with the adjusted R-squared. Normal probability plot of the studied residuals for triple responses are illustrated in Figure 9. These plots are to check the normality of residuals.

TABLE VI. STATISTICAL PARAMETERS OF PRESENTED MODELS FOR THREE RESPONSES

\begin{tabular}{|c|c|c|c|c|}
\hline Statistical parameter & Maximum Misses stress & Maximum Tresca stress & $\begin{array}{c}\text { Maximum ring } \\
\text { displacement }\end{array}$ & Description \\
\hline F-value* & 178.15 & 173.01 & 397.62 & Significant model \\
\hline Adequate Precision & 46.953 & 46.546 & 49.470 & Adequate signal \\
\hline R-Squared & 0.8135 & 0.8090 & 0.8656 & $\begin{array}{c}\text { The Predicted R-Squared is } \\
\text { in reasonable agreement with } \\
\text { the Adjusted R-Squared }\end{array}$ \\
\hline Predicted R-Squared & 0.8021 & 0.7974 & 0.8597 & 0.8634 \\
\hline Adjusted R-squared & 0.8090 & 0.8044 & * There is only a 0.01\% chance that an F-value this large could occur due to noise. \\
\hline \multicolumn{5}{|r|}{}
\end{tabular}
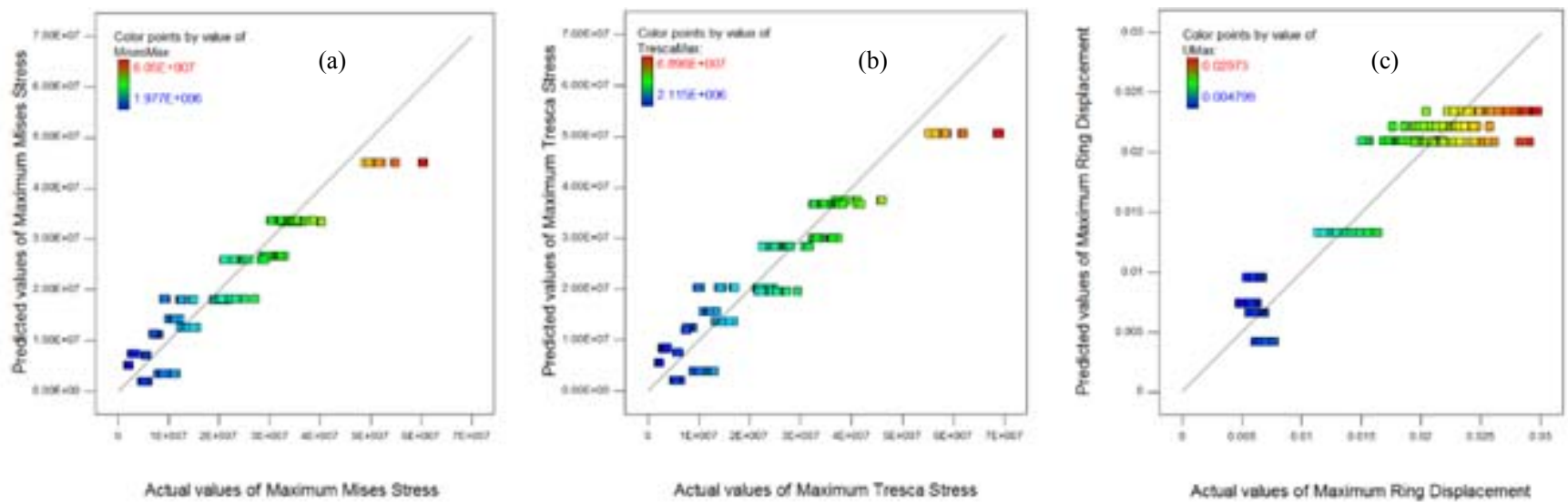

Fig. 8. Actual and predicted values for maximum Mises Stress, Maximum Tresca stress and Maximum ring displacement: (a) Maximum Mises stress (b) Maximum Tresca stress (c) Maximum ring displacement
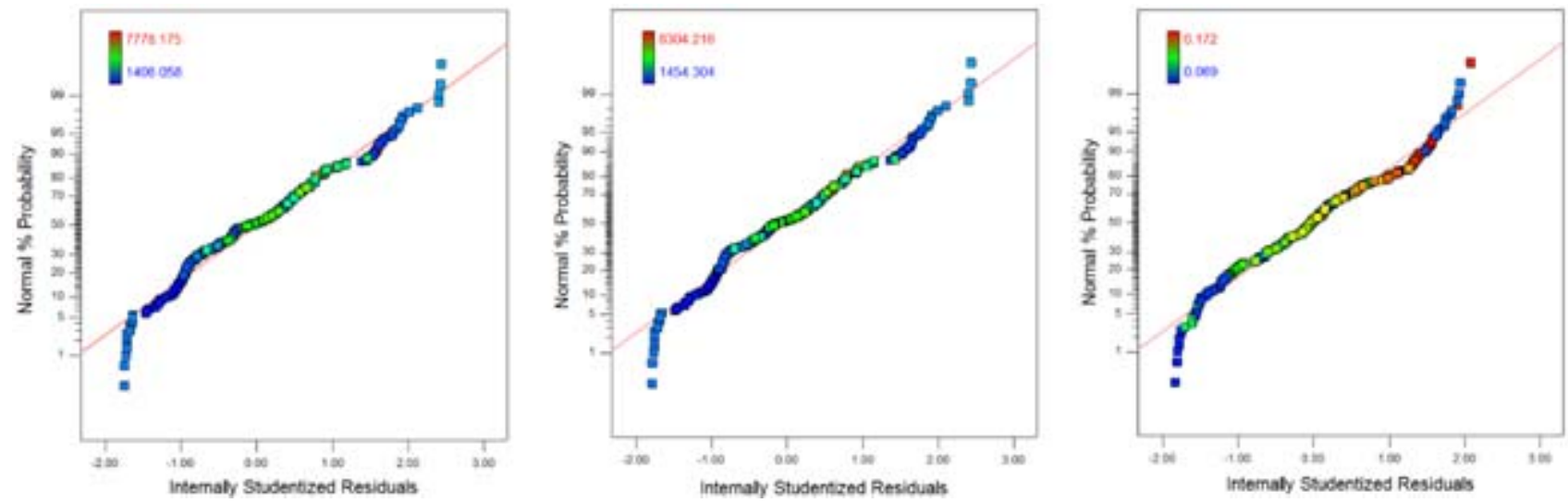

Fig. 9. Plot of Normal probability versus studentized residuals : (a) Maximum Mises stress

(b) Maximum Tresca stress (c) Maximum ring displacement 
If residual points follow a straight line, the normal probability plot indicates that the residuals are normally distributed. The more linear the shape of the normal probability plot, the better the quality of the model.

\section{B. Second-order polynomial models}

In analysis of variance, values of "Prob > F" less than 0.0500 indicate model terms are significant. For maximum Mises stress case, $\mathrm{A}, \mathrm{B}, \mathrm{C}, \mathrm{AB}, \mathrm{B}^{2}, \mathrm{C}^{2}$ are significant model terms, Table VII. Values greater than 0.1000 indicate the model terms are not significant. So the included variables in the equation are tunnel lining thickness, tunnel height and $\mathrm{K}$ ratio.

Final equation in terms of actual factors for Mises maximum stress is as follows (5):

Sqrt $($ MisesMax $)=7052-37.4 *($ Thickness $)+280.2 *($ Height $)-$ $11977.4 *($ K Ratio $)-2.16 *($ Thickness * Height $)-3.03 *(\text { Height })^{2}$ $+6766 *(\text { K Ratio })^{2}$

For maximum Tresca stress case, similar to maximum Mises stress, $\mathrm{A}, \mathrm{B}, \mathrm{C}, \mathrm{AB}, \mathrm{B}^{2}, \mathrm{C}^{2}$ are significant model terms, Table VIII. Final equation in terms of actual factors for Tresca maximum stress is as follows (6):

Sqrt $($ TrescaMax $)=7666.685-43.982 *($ Thickness $)+$ $300.087 *$ (Height)-12816.724*(K Ratio)-2.464*(Thickness* Height) $-3.170 *(\text { Height })^{2}+7232.985 *(\text { K Ratio })^{2}$

For maximum ring displacement case, B, C, BC, C2 are significant model terms, Table IX. So the included variables are tunnel height and $\mathrm{K}$ ratio. Final equation in terms of actual factors for maximum ring displacement is:

Sqrt $($ UMax $)=0.189+4.215 \mathrm{E}-003 *$ (Height) $-0.34 *($ K Ratio $)-$ $2.53 \mathrm{E}-00 *($ Height $* \mathrm{~K}$ Ratio $)+0.206 *(\mathrm{~K} \text { Ratio })^{2}$

C. Response surface analysis of maximum Mises stress, Tresca stress and tunnel ring displacement

The individual and interaction influence of included variables in equations (5) to (7) on responses are shown in Figures 10 to 23. It must be noticed that in the analysis of the influence of each variable on the response, other input parameters are kept in their average values.

TABLE VII. ANOVA FOR MAXIMUM MISES STRESS

\begin{tabular}{|c|c|c|c|c|c|c|}
\hline \multicolumn{7}{|c|}{ Analysis of variance table } \\
\hline Source & $\begin{array}{l}\text { Sum of } \\
\text { Squares }\end{array}$ & $d f$ & $\begin{array}{l}\text { Mean } \\
\text { Square }\end{array}$ & $\begin{array}{c}F \\
\text { Value }\end{array}$ & $\begin{array}{l}p \text {-value } \\
\text { Prob }>F\end{array}$ & \\
\hline Model & $5.157 \mathrm{E}+008$ & 6 & $8.596 \mathrm{E}+007$ & 178.15 & $<0.0001$ & 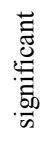 \\
\hline $\begin{array}{c}\text { A- } \\
\text { Thickness } \\
\end{array}$ & $3.070 \mathrm{E}+007$ & 1 & $3.070 \mathrm{E}+007$ & 63.64 & $<0.0001$ & \\
\hline B-Height & $2.162 \mathrm{E}+008$ & 1 & $2.162 \mathrm{E}+008$ & 448.10 & $<0.0001$ & \\
\hline C-K Ratio & $1.015 \mathrm{E}+008$ & 1 & $1.015 \mathrm{E}+008$ & 210.33 & $<0.0001$ & \\
\hline $\mathrm{AB}$ & $1.962 \mathrm{E}+006$ & 1 & $1.962 \mathrm{E}+006$ & 4.07 & 0.0448 & \\
\hline B2 & $5.169 \mathrm{E}+006$ & 1 & $5.169 \mathrm{E}+006$ & 10.71 & 0.0012 & \\
\hline $\mathrm{C} 2$ & $1.602 \mathrm{E}+008$ & 1 & $1.602 \mathrm{E}+008$ & 332.08 & $<0.0001$ & \\
\hline
\end{tabular}

\begin{tabular}{|c|c|c|c|c|c|c|}
\hline \multicolumn{7}{|c|}{ Analysis of variance } \\
\hline Source & $\begin{array}{l}\text { Sum of } \\
\text { Squares }\end{array}$ & $d f$ & $\begin{array}{l}\text { Mean } \\
\text { Square }\end{array}$ & $\begin{array}{c}F \\
\text { Value }\end{array}$ & $\begin{array}{c}\text { p-value } \\
\text { Prob }>F\end{array}$ & \\
\hline Model & $5.836 \mathrm{E}+008$ & 6 & $9.727 \mathrm{E}+007$ & 173.01 & $<0.0001$ & 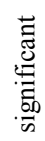 \\
\hline A-Thickness & $4.128 \mathrm{E}+007$ & 1 & $4.128 \mathrm{E}+007$ & 73.42 & $<0.0001$ & \\
\hline B-Height & $2.368 \mathrm{E}+008$ & 1 & $2.368 \mathrm{E}+008$ & 421.19 & $<0.0001$ & \\
\hline C-K Ratio & $1.142 \mathrm{E}+008$ & 1 & $1.142 \mathrm{E}+008$ & 203.20 & $<0.0001$ & \\
\hline $\mathrm{AB}$ & $2.550 \mathrm{E}+006$ & 1 & $2.550 \mathrm{E}+006$ & 4.54 & 0.0342 & \\
\hline $\mathrm{B}^{2}$ & $5.630 \mathrm{E}+006$ & 1 & $5.630 \mathrm{E}+006$ & 10.01 & 0.0018 & \\
\hline $\mathrm{C}^{2}$ & $1.831 \mathrm{E}+008$ & 1 & $1.831 \mathrm{E}+008$ & 325.69 & $<0.0001$ & \\
\hline
\end{tabular}

TABLE IX. ANOVA FOR MAXIMUM LINING RING DISPLACEMENT

\begin{tabular}{|l|l|l|l|l|l|l|}
\hline \multicolumn{1}{|c|}{ Source } & $\begin{array}{c}\text { Sum of } \\
\text { Squares }\end{array}$ & df & $\begin{array}{c}\text { Mean } \\
\text { Square }\end{array}$ & $\begin{array}{c}\boldsymbol{F} \\
\text { Value }\end{array}$ & $\begin{array}{c}\boldsymbol{p} \text {-value } \\
\text { Prob }>\boldsymbol{F}\end{array}$ & \\
\hline Model & 0.26 & 4 & 0.065 & 397.62 & $<0.0001$ & significant \\
\hline B-Height & 0.048 & 1 & 0.048 & 289.93 & $<0.0001$ & \\
\hline C-K Ratio & 0.048 & 1 & 0.048 & 291.23 & $<0.0001$ & \\
\hline BC & 0.018 & 1 & 0.018 & 108.81 & $<0.0001$ & \\
\hline C2 & 0.15 & 1 & 0.15 & 900.50 & $<0.0001$ & \\
\hline
\end{tabular}

According to Figure 10, as tunnel lining thickness increases in its range, the maximum Mises stress decreases slightly. Maximum Mises stress increases when tunnel height value increases from $5.0 \mathrm{~m}$ up to $25 \mathrm{~m}$, Figure 11. By increasing $\mathrm{K}$ ratio from 0.5 to unity (hydrostatic condition), maximum Mises stress decreases, and consequently increases when $\mathrm{K}$ ratio increases from unity up to 1.5 , Figure 12 . As can be seen from Figure 13, simultaneously increasing both in lining thickness and tunnel height variables cause reduction in maximum Mises stress, but tunnel height variable has more influence on maximum Mises stress reduction than lining thickness variable. In a constant value of lining thickness, as $\mathrm{K}$ stress ratio increases up to unity, the maximum Mises stress decreases, and then increase mutually with $\mathrm{K}$ ratio. This trend can be seen in all constant values of lining thickness. This effect is shown in Figure 14 three dimensionally.

Analysis of variance showed that regression equations of maximum Mises stress and maximum Tresca stress, both include the same terms. As illustrated in Figures 15-18, lining thickness, tunnel height, $\mathrm{K}$ ratio and thickness-height interaction have the same effect on maximum Tresca stress as those effect on maximum Mises stress. In a constant value of tunnel height, as lining thickness increases from $30 \mathrm{~cm}$ up to 40 $\mathrm{cm}$, maximum Tresca stress decreases slightly, but the rate of reduction in maximum Tresca stress is greater in higher values of tunnel height (Figure 19).

For maximum displacement of a tunnel lining ring (Umax), as tunnel height increases, maximum tunnel lining displacement increases (Figure 20). By increasing $\mathrm{K}$ ratio from 0.5 to unity (hydrostatic condition), maximum ring displacement decreases and consequently, increase mutually when $\mathrm{K}$ ratio increases from unity to 1.5 (Figure 21). 


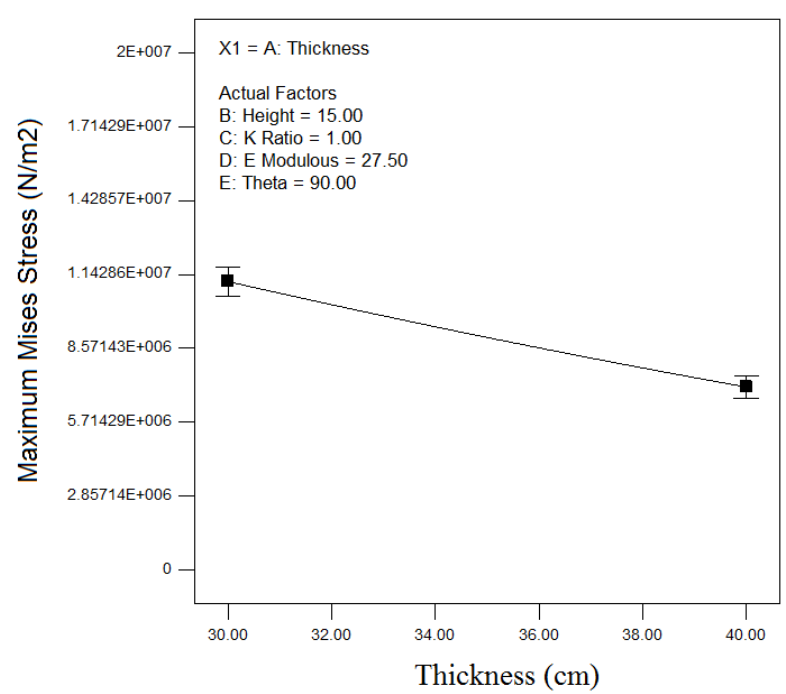

Fig. 10. The effect of lining thickness on maximum Mises thickness

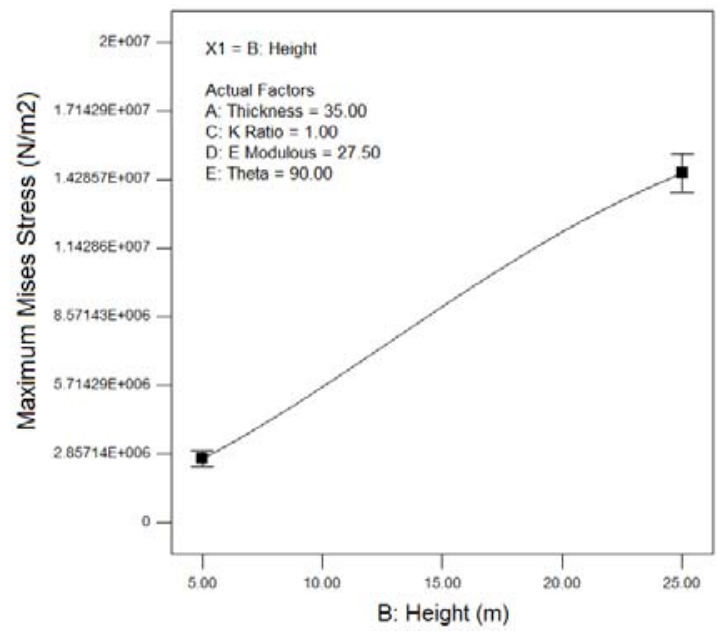

Fig. 11. The effect of tunnel height on maximum Mises stress

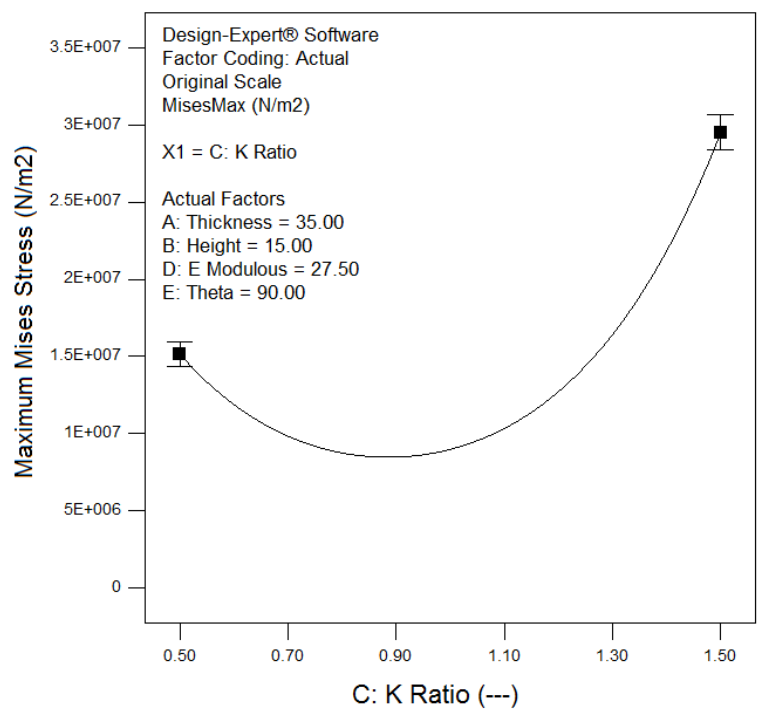

Fig. 12. The effect of $\mathrm{K}$ ratio on maximum Mises stress

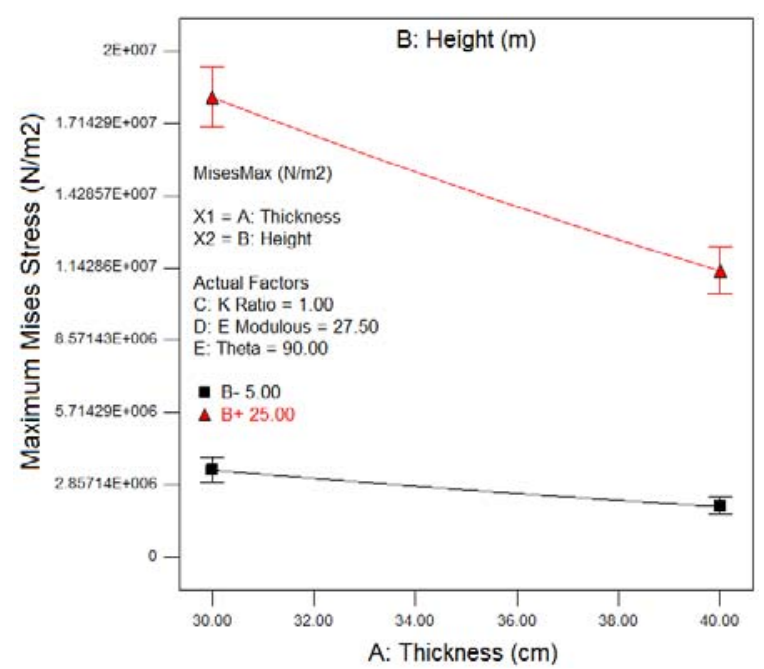

Fig. 13. The effect of thickness and height interaction in 2D plane on maximum Mises stress

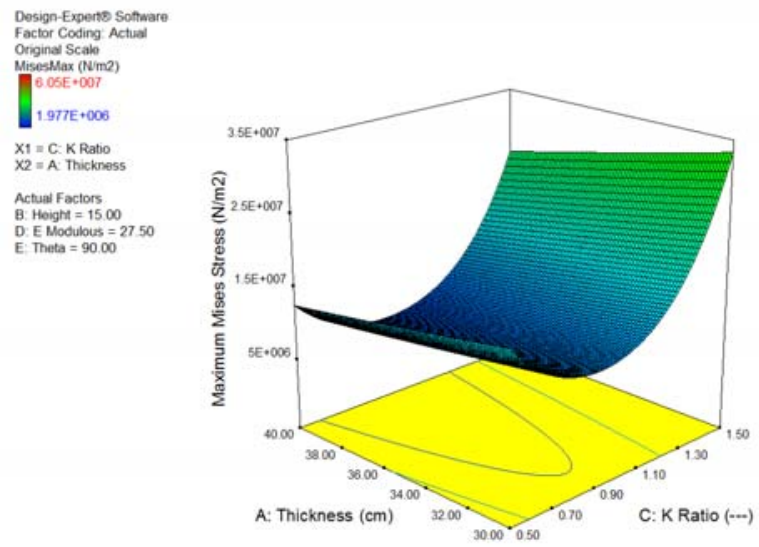

Fig. 14. The effect of thickness and height interaction in 3D space on maximum Mises stress

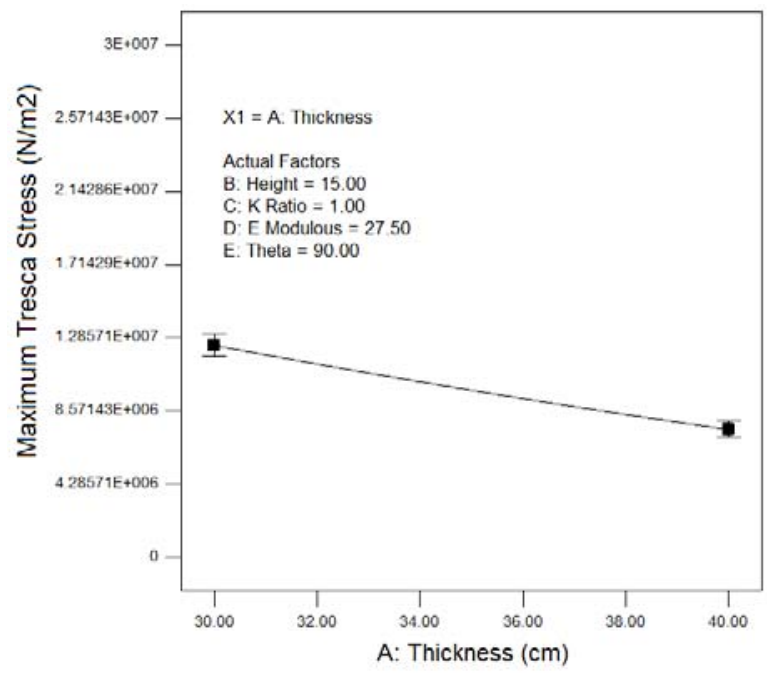

Fig. 15. The effect of lining thickness on maximum Tresca stress 


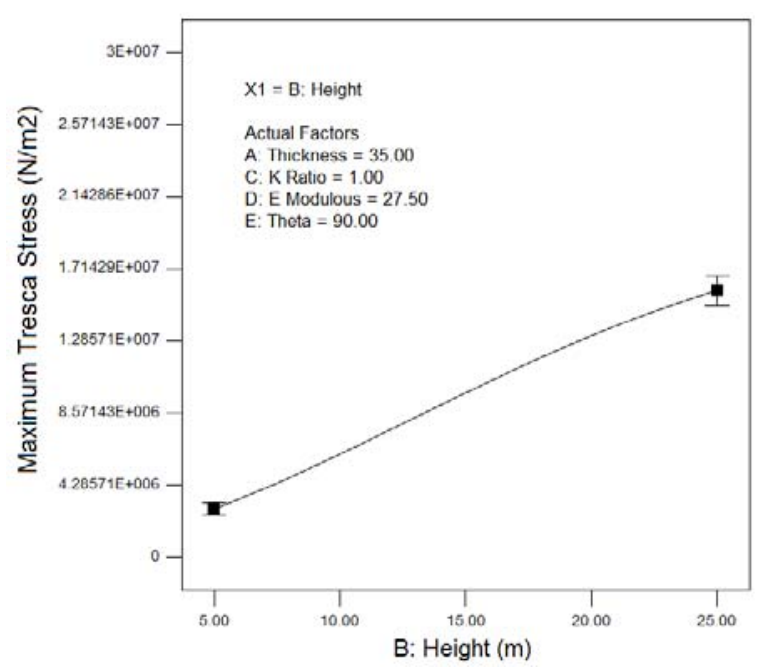

Fig. 16. The effect of tunnel height on maximum Tresca stress

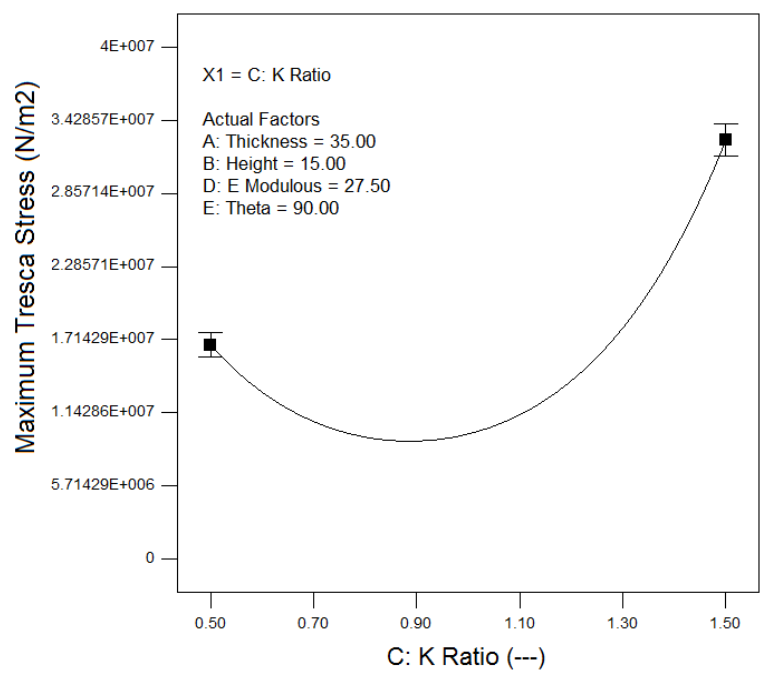

Fig. 17. The effect of $\mathrm{K}$ ratio on maximum Tresca stress

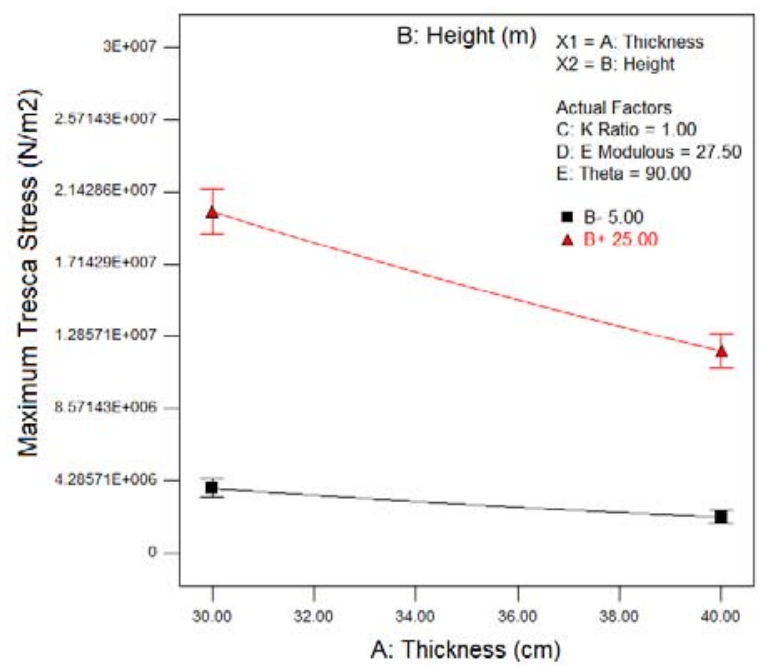

Fig. 18. The effect of thickness and height interaction in 2D plane on maximum Tresca stress

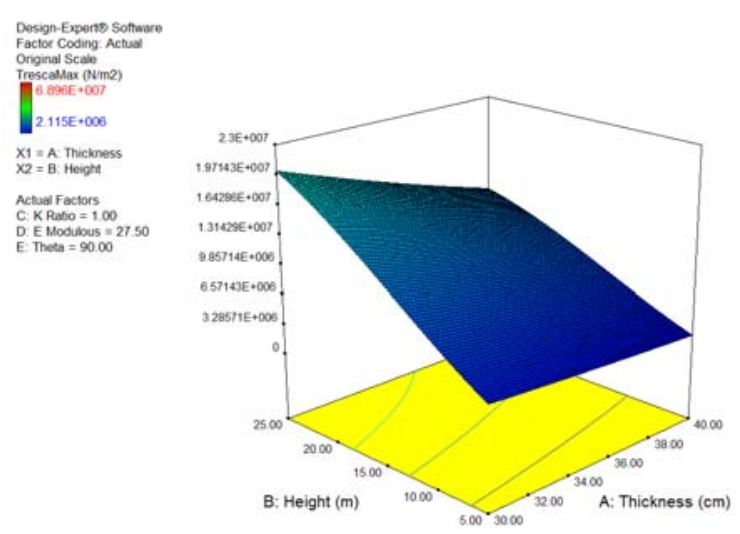

Fig. 19. The effect of thickness and height interaction in 3D space on maximum Tresca stress

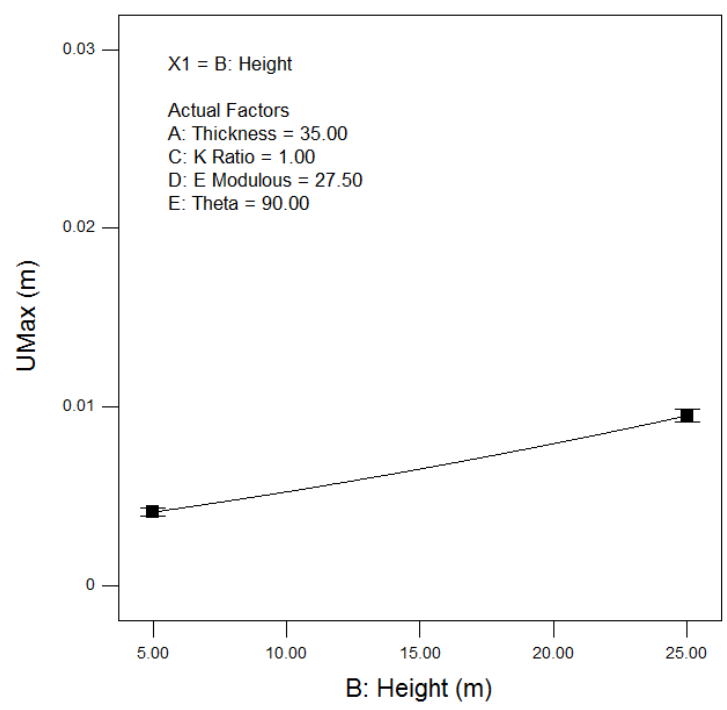

Fig. 20. The effect of tunnel height on maximum lining ring displacement

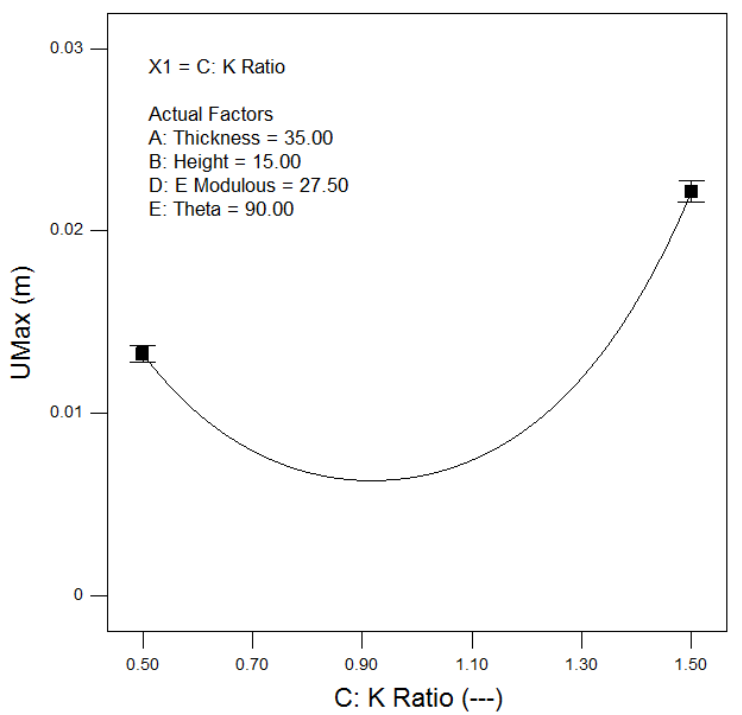

Fig. 21. The effect of tunnel height on maximum lining ring displacement 


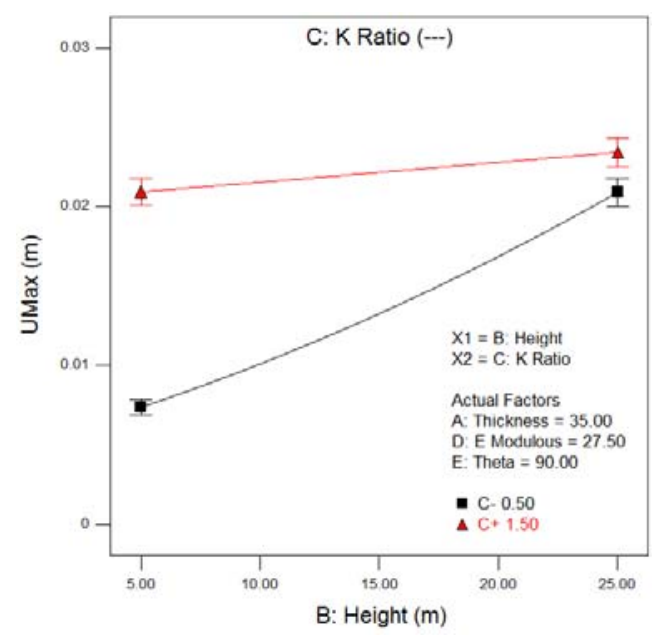

Fig. 22. The effect of tunnel height and $\mathrm{k}$ ratio interaction in 2D plane on maximum lining ring displacement

As it can be seen from Figure 22, increasing simultaneously both in tunnel height and $\mathrm{K}$ ratio variables increases the maximum ring displacement, but tunnel height variable has more influence to increase the maximum ring displacement than $\mathrm{K}$ ratio variable. In all constant values of $\mathrm{K}$ ratio, as tunnel height increases, the maximum ring displacement increases slightly. This effect is shown dimensionally in Figure 23.

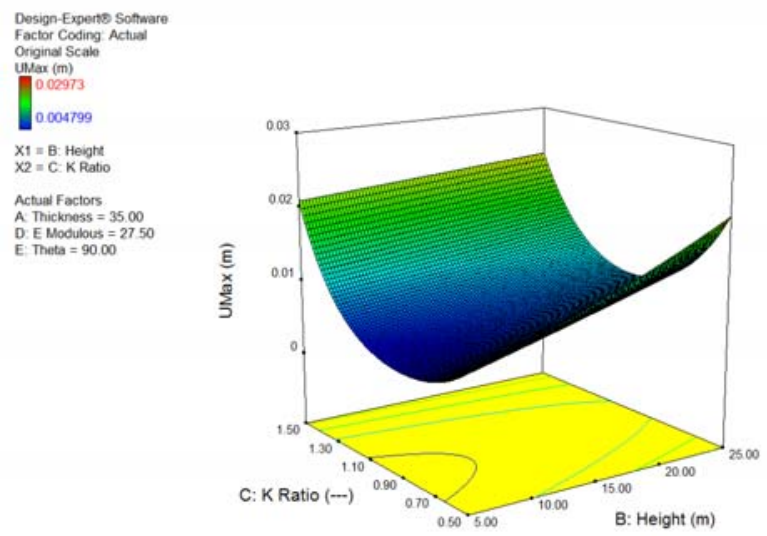

Fig. 23. The effect of tunnel height and $\mathrm{k}$ ratio interaction in 3D space on maximum lining ring displacement

\section{Optimization}

Structural optimization based on FEM requires special computational tools. This attempt has become a major part in this field of study, where optimization seems to be a mandatory process in design and economical points of view. Optimization using numerical methods needs considerable computational cost and most likely is time consuming based on the complexity of the problem. Application of FE based response surface methodology is an alternative solution to reduce computational cost and time of analysis considerably without deficiency in the models. Therefore, to obtain an optimum structure for segmental tunnel lining both from geometrical and engineering point of view, at first constraints, goals and importance order of each input and response parameter were set according to Table X. Since the analysis of variance showed that elasticity modulus and key segment position variables are not involved in response equations, so their values were kept constant in average level during optimization process. Domain of other input variables, i.e. tunnel lining thickness, tunnel height and $\mathrm{K}$ ratio were set into their ranges. To optimize the tunnel lining structure, response parameters, i.e. maximum Mises and Tresca stresses and maximum lining ring displacement were set to their minimum values. After optimization process, obtained results are presented in Table XI.

TABLE $X . \quad$ GOALS AND CONSTRAINTS OF VARIABLES AND RESPONSES

\begin{tabular}{|c|c|c|c|c|}
\hline \multicolumn{5}{|c|}{ Constraints } \\
\hline Name & Goal & $\begin{array}{c}\text { Lower } \\
\text { Limit }\end{array}$ & $\begin{array}{c}\text { Upper } \\
\text { Limit }\end{array}$ & Importance \\
\hline A:Thickness & is in range & 30 & 40 & 3 \\
\hline B:Height & is in range & 5 & 25 & 3 \\
\hline C:K Ratio & is in range & 0.5 & 1.5 & 3 \\
\hline D:E Modulus & average & 20 & 35 & 3 \\
\hline E:Theta & average & 0 & 180 & 3 \\
\hline MisesMax & minimize & $1.977 \mathrm{E}+006$ & $6.05 \mathrm{E}+007$ & 3 \\
\hline TrescaMax & minimize & $2.115 \mathrm{E}+006$ & $6.896 \mathrm{E}+007$ & 3 \\
\hline UMax & minimize & 0.004799 & 0.02973 & 5 \\
\hline
\end{tabular}

One hundred solutions were proposed by the statistical analysis. Although, desirability index was equal to unity in all proposed solutions, but the best solution is underlined in first row of Table XI. Plots of ramp display for best solution is shown in Figure 24. Optimum values of variables and responses are shown.

TABLE XI. PROPOSED SOLUTIONS TO OPTIMIZE TUNNEL LINING CHARACTERISTICS

\begin{tabular}{|c|c|c|c|c|c|c|c|c|c|}
\hline \multicolumn{10}{|c|}{ Solutions: } \\
\hline No. & $\begin{array}{c}\text { Thickness } \\
(\mathbf{c m})\end{array}$ & $\begin{array}{c}\text { Height } \\
(\mathbf{m})\end{array}$ & $\begin{array}{c}\text { K Ratio } \\
(--)\end{array}$ & $\begin{array}{c}\boldsymbol{E} \\
\text { Modulous } \\
(\mathbf{G p a})\end{array}$ & Theta $^{*}(\boldsymbol{)})$ & $\begin{array}{c}\text { MisesMax } \\
\left(\mathbf{N} / \mathbf{m}^{2}\right)\end{array}$ & $\begin{array}{c}\text { TrescaMax } \\
\left(\mathbf{N} / \mathbf{m}^{2}\right)\end{array}$ & $\begin{array}{c}\text { UMax } \\
(\mathbf{m})\end{array}$ & $\begin{array}{c}\text { Desirability } \\
\text { Index }\end{array}$ \\
\hline 1 & 38.595 & 5. & 0.864 & 27.5 & 90 & 1972897.422 & 2104034.290 & 0.004 & 1 \\
\hline 2 & 39.9 & 5.3 & 0.88 & 27.5 & 90 & 1960092.90 & 2069289.145 & 0.0037 & 1 \\
\hline 3 & 39. & 5.07 & 0.853 & 27.5 & 90 & 1958046.11 & 2082296.28 & 0.0036 & 1 \\
\hline 4 & 39.7 & 5.08 & 0.94 & 27.5 & 90 & 1911454.36 & 2020534.00 & 0.0038 & 1 \\
\hline 5 & 39.7 & 5.02 & 0.80 & 27.5 & 90 & 1951520.38 & 2068656.82 & 0.0037 & 1 \\
\hline 6 & 39.5 & 5.10 & 0.84 & 27.5 & 90 & 1917118.97 & 2031757.06 & 0.0036 & 1 \\
\hline$\ldots$ & $\ldots$ & $\ldots$ & $\ldots$ & $\ldots$ & $\ldots$ & $\ldots$ & $\ldots$ & $\ldots$ & $\ldots$ \\
\hline 100 & 34.4 & 5.0 & 0.852 & 27.5 & 90 & 2502924.69 & 2740456.29 & 0.0036 & 1 \\
\hline
\end{tabular}




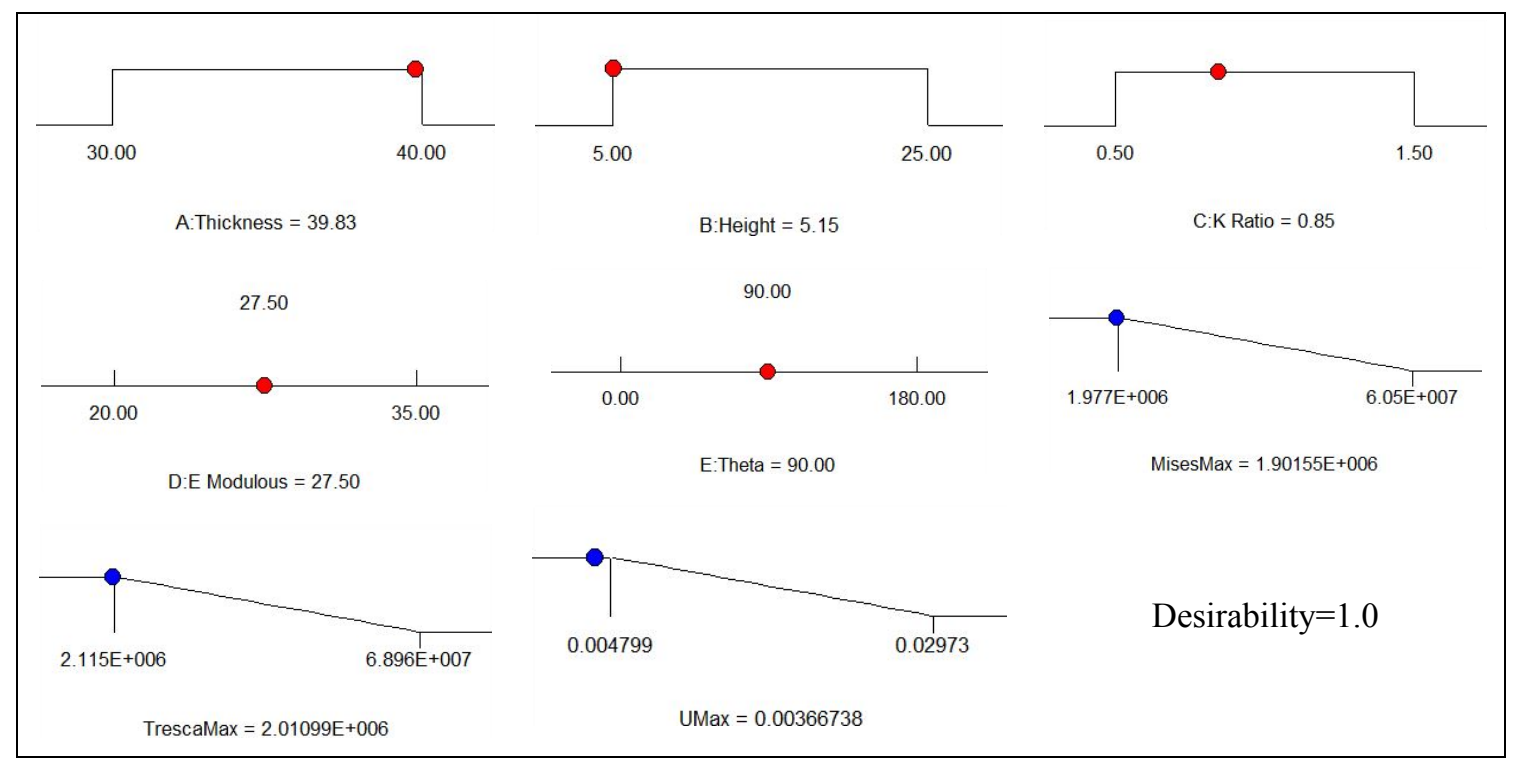

Fig. 24. Optimized values: red and blue circles represent input variables and responses, respectively.

From the optimization process it is concluded that to obtain minimum values for each three response parameters, ring thickness and tunnel height must be near to their maximum and minimum values, respectively and the tunnel lining must be embedded nearly in hydrostatic condition of the ground, i.e. a $\mathrm{K}$ ratio of 1 . On the other hand, the higher values for tunnel lining thickness together with the lower values for tunnel height simultaneously, will induce both the minimum values for Mises and Tresca stress values and the displacement of tunnel lining ring in nearly hydrostatic ground conditions.

\section{CONCLUSIONS}

FEM based response surface methodology was applied to prepare prediction models for segmental tunnel lining. Quadratic regression equation was applied in RSM to establish equations between five input variables and three responses. Obtained models were used to determine the maximum Mises and Tresca stresses and lining ring displacement generated in one ring of tunnel lining. Analysis of variance was used to discuss about the influence of each independent input variable and their interactions on response parameters. For the three responses, the evaluation of the fitted models are performed by the regression coefficient. Presented models approximately had acceptable values of regression. The terms in maximum Mises and Tresca stresse models were the same: concrete segment thickness $(\mathrm{t})$, tunnel overburden $(\mathrm{H})$ and stress ratio $(\mathrm{K})$. The terms in maximum ring displacement model were tunnel overburden $(\mathrm{H})$ and stress ration $(\mathrm{K})$, i.e. concrete segment thickness and elasticity modulus of concrete segments and key position had no considerable effect on maximum ring displacement. It is found that tunnel height variable influenced the responses more than both segment thickness and $\mathrm{K}$ ratio variables in stress and displacement models, respectively. In the optimization process, it is concluded that to obtain minimum values for responses, ring thickness and tunnel height must be near to their maximum and minimum values, respectively and the tunnel must be embedded nearly in hydrostatic condition of the ground, i.e. a $\mathrm{K}$ ratio of 1.

\section{REFERENCES}

[1] V. Guglielmetti, P. Grasso, A. Mahtab, S. Xu, Mechanized tunnelling in urban areas: design methodology and construction control, CRC Press, 2008

[2] J. B. O'Carroll, A Guide to Planning, Constructing, and Supervising Earth Pressure Balance TBM Tunneling, Parsons Brinckerhoff, 2005

[3] R. G. A. de Waal, Steel fibre reinforced tunnel segments-for the application in shield driven tunnel linings, TU Delft, Delft University of Technology, 2000

[4] C. B. M. Blom, Design philosophy of concrete linings for tunnels in soft soils, TU Delft, Delft University of Technology, 2002

[5] A. Majdi, H. Ajamzadeh, K. Emad, "Numerical evaluation of the influence of bolted-and non-bolted joints on segmental tunnel lining behavior in line 4 Tehran subways", 6th Asian Rock Mechanics Symposium - Advances in Rock Engineering, New Delhi, India, October $23-27,2010$

[6] A. M. Wood, "The circular tunnel in elastic ground", Geotechnique, Vol. 25, No. 1, pp. 115-127, 1975

[7] H. Duddeck, J. Erdmann, Structural design models for tunnels in soft soil, Underground Space, United States, 1985

[8] I. Hudoba, "Contribution to static analysis of load-bearing concrete tunnel lining built by shield-driven technology", Tunnelling and Underground Space Technology, Vol. 12, No. 1, pp. 55-58, 1997

[9] I. W. Group, "Guidelines for the design of shield tunnel lining", Tunnelling and Underground Space Technology, Vol. 15, No. 3, pp. 303-331, 2000

[10] K. M. Lee, X. Y. Hou, X. W. Ge, Y. Tang, "An analytical solution for a jointed shield-driven tunnel lining", International Journal for Numerical and Analytical Methods in Geomechanics, Vol. 25, No. 4, pp. 365-390, 2001

[11] Y. Koyama, "Present status and technology of shield tunneling method in Japan", Tunnelling and Underground Space Technology, Vol. 18, No. 2, pp. 145-159, 2003

[12] F. Grübl, M. Thewes, "Recommendations of the German working group on design and calculation of shield machines", Tunnelling and Underground Space Technology, Vol. 21, No. 3, pp. 261-261, 2006 
[13] L. Lu, X. Lu, P. Fan, "Full-ring experimental study of the lining structure of Shanghai Changiiang tunnel", 4th International Conference on Earthquake Engineering, Taipei, Taiwan, 2006

[14] S. Teachavorasinskun, T. Chub-Uppakarn, "Experimental verification of joint effects on segmental tunnel lining", Electronic Journal of Geotechnical Engineering, Vol. 14, pp. 1-8, 2008

[15] N. Do, D. Dias, P. Oreste, I. Djeran-Maigre, "2D numerical investigation of segmental tunnel lining behavior", Tunnelling and Underground Space Technology, Vol. 37, pp. 115-127, 2013

[16] H. Morgan, "A contribution to the analysis of stress in a circular tunnel", Geotechnique, Vol. 11, No. 1, pp. 37-46, 1961

[17] R. E. Ranken, J. Ghaboussi, A. Hendron Jr, Analysis of ground-liner interaction for tunnels, Department of Transportation, Office of the Secretary , USA, 1978

[18] C. W. Schwartz, H. H. Einstein, "Simplified Analysis For Groundstructurinet Eraction In Tunneling", 21st US Symposium on Rock Mechanics (USRMS), American Rock Mechanics Association, 1980

[19] Japan Society of Civil Engineers, Japanese Standard for Shield Tunnelling, Tokyo,Japan, JSCE, 1996

[20] S. Liao, F. Peng, S. Shen, "Analysis of shearing effect on tunnel induced by load transfer along longitudinal direction", Tunnelling and Underground Space Technology, Vol. 23, No. 4, pp. 421-430, 2008

[21] C. Carranza-Torres, B. Rysdahl, M. Kasim, "On the elastic analysis of a circular lined tunnel considering the delayed installation of the support", International Journal of Rock Mechanics and Mining Sciences, Vol. 61, pp. 57-85, 2013

[22] N. Do, D. Dias, P. Oreste, "3D numerical investigation of mechanized twin tunnels in soft ground-Influence of lagging distance between two tunnel faces", Engineering Structures, Vol.109, pp. 117-125, 2016

[23] N. Do, D. Dias, P. Oreste, I. Djeran-Maigre, "Behaviour of segmental tunnel linings under seismic loads studied with the hyperstatic reaction method", Soil Dynamics and Earthquake Engineering, Vol. 79, Part A, pp. $108-117,2015$
[24] N. Do, D. Dias, P. Oreste, "3D numerical investigation on the interaction between mechanized twin tunnels in soft ground", Environmental Earth Sciences, Vol. 73, No. 5, pp. 2101-2113, 2015

[25] N. Do, D. Dias, P. Oreste, I. Djeran-Maigre, "2D numerical investigation of segmental tunnel lining under seismic loading”, Soil Dynamics and Earthquake Engineering, Vol. 72, pp. 66-76, 2015

[26] ABAQUS/CAE User's Manual, Hibbitt, Karlsson \& Sorensen, Inc. 2014

[27] H. Schulze, H. Duddeck, "Spannungen in schildvorgetriebenen Tunneln", Beton-und Stahlbetonbau, Vol. 59, No. 8, pp. 169-175, 1964

[28] U. A. C. O. Engineering, Tunnels and Shafts in Rock Engineer Manual, EM 1110-2-2901. Dept. of the Army, Corps of Engineers, Washington, DC, 1997

[29] German Committee for Underground Construction, Recommendations for static analysis of shield tunnelling machines. Tunnel. 7, pp. 44-58, 2005

[30] K. Bakker, "Structural design of linings for bored tunnels in soft ground", Heron, Vol. 48, No. 1, pp. 33-63, 2003

[31] T. Telford, Tunnel lining design guide, British Tunneling Society and the Institution of Civil Engineers. 2004

[32] X. Huang, H. Huang, J. Zhang, "Flattening of jointed shield-driven tunnel induced by longitudinal differential settlements", Tunnelling and Underground Space Technology, Vol. 31, pp. 20-32, 2012

[33] F. Ye, C. Gou, H. Sun, Y. Liu, Y. Xia, Z. Zhou, "Model test study on effective ratio of segment transverse bending rigidity of shield tunnel", Tunnelling and Underground Space Technology, Vol. 41, pp. 193-205, 2014

[34] F. Barpi, M. Barbero, D. Peila, "Numerical modelling of ground-tunnel support interaction using bedded-beam-spring model with fuzzy parameters", Gospodarka Surowcami Mineralnymi, Vol. 27, pp. 71-87, 2011

[35] R. H. Myers, D. C. Montgomery, C. M. Anderson-Cook, Response surface methodology: process and product optimization using designed experiments, John Wiley \& Sons, 2016

[36] D. C. Montgomery, Design and analysis of experiments. John Wiley \& Sons, 2008 